\title{
Retracted: Human Interferon Inducible Transmembrane Protein 3 (IFITM3) Inhibits Influenza Virus A Replication and Inflammation by Interacting with ABHD16A
}

\author{
BioMed Research International \\ Received 5 March 2022; Accepted 5 March 2022; Published 6 April 2022 \\ Copyright (c) 2022 BioMed Research International. This is an open access article distributed under the Creative Commons \\ Attribution License, which permits unrestricted use, distribution, and reproduction in any medium, provided the original work \\ is properly cited.
}

BioMed Research International has retracted the article titled "Human Interferon Inducible Transmembrane Protein 3 (IFITM3) Inhibits Influenza Virus A Replication and Inflammation by Interacting with ABHD16A" [1] due to concerns with the reliability of the data. We have been made aware of a number of concerns and inconsistencies with the data and results presented. Specifically, the images presented in Figure 2(b) do not correspond to the stains used and the blots in Figure 1, 3, and 4 do not correspond to the experiment described. The article was also found to contain a substantial amount of material from the two thesis articles $[2,3]$.

The authors contacted the journal to request the retraction of the article due to these concerns, explaining that the research was conducted by an external company. With the agreement of the authors and the editorial board the article is being retracted from the journal.

\section{References}

[1] C. Liang, L. Zhu, and J. Chen, "Human Interferon Inducible Transmembrane Protein 3 (IFITM3) Inhibits Influenza Virus A Replication and Inflammation by Interacting with ABHD16A," BioMed Research International, vol. 2021, Article ID 6652147, 9 pages, 2021.

[2] C. Xu, Porcine IFITM Inhibits Japanese Encephalitis Virus by Interacting with ABHD16A, Henan Agricultural University, Henan, 2018.

[3] G. Weizhen, A Preliminary Study on the Interaction between Human ABHD16A and IFITMs, Henan Agricultural University, Henan, 2018. 


\title{
Human Interferon Inducible Transmembrane Protein 3 (IFITM3)
} Inhibits Influenza Virus A Replication and Inflammation by Interacting with ABHD16A

\author{
Liang Chen $\mathbb{D}^{1},{ }^{1}$ Limei Zhu $\mathbb{D}^{2},{ }^{2}$ and Jun Chen $\mathbb{D}^{3}$ \\ ${ }^{1}$ Department of Infectious Diseases, Beijing Jishuitan Hospital, Beijing, China \\ ${ }^{2}$ Department of Chronic and Infectious Diseases Control, Jiangsu Provincial Center for Disease Control and Prevention, \\ Nanjing, China \\ ${ }^{3}$ Department of Pathology, Nanjing Drum Tower Hospital, Nanjing, China \\ Correspondence should be addressed to Liang Chen; chenliang1995@sina.com
}

Received 5 October 2020; Revised 11 January 2021; Accepted 20 February 2021; Published 3 March 2021

Academic Editor: Lester J. P rez

Copyright (C) 2021 Liang Chen et al. This is an open access article distributed under the Creative Commons Attribution License, which permits unrestricted use, distribution, and reproduction in any medium, provided the original work is properly cited.

Studies have shown that human interferon inducible transmembrane protein (hIFITMs) family proteins have broad-spectrum antiviral capabilities. Preliminary studies in our laboratory have tentatively proved that hIFITMs have the effect of inhibiting influenza viruses. In order to further study its mechanism and role in the occurrence and development of influenza A, relevant studies have been carried out. Fluorescence quantitative polymerase chain reaction (PCR) detection technology was used to observe the effect of hIFITM3 on the replication of influenza A virus (IVA) and the interaction with hABHD16A. In HEK293 cells, overexpression of hIFITM3 protein significantly inhibited the replication of IVA at $24 \mathrm{~h}, 48 \mathrm{~h}$, and $72 \mathrm{~h}$; yeast two-hybrid experiment proved that hIFITM3 interacts with hABHD16A; laser confocal microscopy observations showed that hIFITM3 and hABHD16A colocalized in the cell membrane area; the expression level of inflammation-related factors in cells overexpressing hIFITM3 or hABHD16A was detected by fluorescence quantitative PCR, and the results showed that the mRNA levels of interleukin- (IL-) $1 \beta$, IL-6, IL-10, tumor necrosis factor- (TNF-) $\alpha$, and cyclooxygenase 2 (COX2) were significantly increased. But when hIFITM3/hABHD16A was coexpressed, the mRNA expression levels of these cytokines were significantly reduced except COX2. When influenza virus infected cells coexpressing hIFITM3/hABHD16A, the expression level of inflammatory factors decreased compared with the control group, indicating that hIFITM3 can play an important role in regulating inflammation balance. This study confirmed that hIFITM3 has an effect of inhibiting IVA replication. Furthermore, it was found that hIFITM3 interacts with hABHD16A, following which it can better inhibit the replication of influenza virus and the inflammatory response caused by the disease process.

\section{Introduction}

Influenza virus is a representative strain of the Orthomyxoviridae family and includes human influenza virus and animal influenza virus (such as swine influenza virus, equine influenza virus, and avian influenza virus) [1]. There are four types of influenza viruses identified, namely, A, B, C, and D. Since the antigenicity of influenza $A$ virus is extremely prone to mutation, it causes a high fatality rate in affected populations, is associated with rapid spread, and has been responsible for pandemics on multiple occasions; as such, it poses a serious challenge to medical communities as well as society as a whole. Due to the lack of drugs that are effective in treating such infectious diseases, outcomes and prognosis depend to a large extent on the elimination of pathogens by the body's own immune system [2].

Interferon-induced transmembrane proteins (IFITMs) are a class of host restriction factors that have been discovered in recent years. They can inhibit the proliferation of enveloped and nonenveloped viruses and are associated with a particular constitutive expression in a variety of cells [3]. It has been confirmed that IFITM3 can resist the infection of 
various viruses, including West Nile virus, influenza virus, and dengue fever. IFITM3 achieves an antiviral infection effect in a variety of ways $[4,5]$. Studies on posttranscriptional modifications of IFITM3 have shown that IFITM3 can be modified by ubiquitination and palmitoylation, and these modifications regulate the cellular localization of IFITM3 and its antiviral function in different ways. Although research on the antiviral mechanism of IFITM3 has targeted the virus entry process, the specific mechanism is not yet clear.

Our preliminary research showed that overexpression of hlFITM3 significantly affected the replication of influenza virus. The purpose of this study was to further examine the anti-influenza virus effect of hlFITM3, its antiviral mechanism, and to inhibit the occurrence of inflammation during the replication of influenza virus with hlFITM3. A preliminary exploration of the mechanism was also conducted. The study of the hlFITM3 interacting protein and the regulation of this interaction in the inflammatory response caused by influenza virus infection can improve our understanding of the antiviral mechanism of IFITMs and provide a theoretical basis for the prevention and control of influenza.

\section{Materials and Methods}

2.1. Cell Culture. HEK293 cells were purchased from Shanghai Cell Bank, Chinese Academy of Sciences. All cells were grown in Dulbecco's modified Eagle's medium (DMEM) (Abcam, USA) with 10\% fetal bovine serum and 1\% antibiotics (penicillin and streptomycin). The cell culture was carried out in humidified air at $37^{\circ} \mathrm{C}$ containing $5 \% \mathrm{CO}_{2}$. All cultures used standardized cell culture.

2.2. Construction of hlFITM3 Eukaryotic Expression Vector. After the total RNA of the cell was extracted, the first strand of cDNA was synthesized. The primers of the hABHD16A and hIFITM3 genes connected to the pEGFP-N1 vector and pCDNA3.1 vector are shown in Table 1.

Subsequently, the target gene was amplified, recovered, digested, ligated, and prepared for transformation to DH5a competent cells, and the recombinant plasmids were verified.

2.3. Plasmid Transfection. On the day before transfection, $2 \times 10^{5}$ HEK293 cells were inoculated in a 6-well plate, with $2 \mathrm{~mL}$ of complete medium (without double antibodies) per well, and placed in a cell incubator, so that the cell density before transfection was about $60.70 \%$. $4 \mu \mathrm{g}$ DNA and $8 \mu \mathrm{L}$ POLO deliverer 3000 were diluted in $50 \mu \mathrm{L}$ DMEM medium per well, mixed, and placed at room temperature for $5 \mathrm{~min}$. The diluted solution of POLO deliverer 3000 was added dropwise to the diluted DNA solution, mixed gently, and left to stand at room temperature for $15 \mathrm{~min}$. The above mixture was added dropwise to the cells in the 6-well plate and shaken gently. The transfected cells were cultured at $37^{\circ} \mathrm{C}$ and $5 \% \mathrm{CO}_{2}$ for $48-72 \mathrm{~h}$, and the medium was changed $12 \mathrm{~h}$ after transfection. $48 \mathrm{~h}$ after the completion of transfection, an inverted green fluorescence microscope was used to observe the expression of green fusion protein.
2.4. Viral Infection. On the day before transfection, $6 \times 10^{4}$ cells were plated in a 24 -well plate, and the positive plasmid carrying the target fragment was transfected into the cells. After $24 \mathrm{~h}$ of transfection, the complete medium was removed, 1x PBS was added, and the cell surface was washed 3 times. IVA diluent was added at 1 MOI (multiplicity of infection) and adsorbed in a $37^{\circ} \mathrm{C}$ and $5 \% \mathrm{CO}_{2}$ incubator for $2 \mathrm{~h}$. During this period, the samples were gently shaken every $30 \mathrm{~min}$. After adsorption, the virus solution was removed, and $0.5 \mathrm{~mL}$ of DMEM complete medium containing $10 \%$ fetal bovine serum (FBS) was added to each 24well plate and cultured at $37^{\circ} \mathrm{C}$ and $5 \% \mathrm{CO}_{2}$. The culture supernatants were taken $24 \mathrm{~h}, 48 \mathrm{~h}$, and $72 \mathrm{~h}$ after infection, and viral RNA was extracted according to the following viral RNA extraction (Takara Corporation, Japan) method.

2.5. Reverse Transcription-PCR (RT-PCR). A PrimeScript miRNA RT kit (Takara Corporation, Japan) was used to reversely transcribe RNA into CDNA. RT-PCR was performed with a SYBR Green RT-PCR Kit $(1: 200$, Takara Corporation, Japan). GADPH served as an internal control for RNA detection.

2.6. Western Blot. Proteins were extracted from cells using RIPA lysis buffer (Beyotime Biotechnology, China) containing protease inhibitors. A BCA protein detection kit was used for protein quantification. Protein separation was performed using $10 \%$ sodium dodecyl sulfate-polyacrylamide gel electrophoresis (SDS-PAGE). Then, the protein was transferred to a polyvinylidene fluoride (PVDF) membrane. The membrane was sealed with $5 \%$ skim milk. The membrane was subsequently incubated with the primary antibody $(1: 200)$ and then with the secondary antibody $(1: 2000)$. The antibodies used in this study were acquired from ABCAM, USA, and were subsequently tested to obtain images.

2.7. Statistical Processing. Statistical analysis was conducted using SPSS19.0 statistical software. Measurement data with a normal distribution and uniform variance were expressed as the mean \pm standard deviation, and the univariate analysis of variance or repeated measurement was used to compare multiple groups of means, and the LSD $t$-test was used for further pairwise comparison. $P<0.05$ was considered statistically significant.

\section{Results}

3.1. Construction of hlFITM3 Eukaryotic Expression Vector. Through gene cloning and vector construction, the results were verified by PCR and sequencing, and two types of eukaryotic fusion expression vectors pcDNA3.1-HA-hlFITM3 and pEGFP-N1-hlFITM3 were successfully constructed (Figures 1(a) and 1(b)).

The PCR results showed (Figure 1(c)) that the vectors used to knock out the hlFITM3 gene were constructed successfully: pHMG-hRNA-hhRNAlFITM3.

3.2. Overexpression of hlFITMs Has an Inhibitory Effect on Influenza Virus Replication. After transfecting HEK293 cells with pEGFP-N1-hlFITM3 and pcDNA3.1-HA-hlFITM3 for 
TABLE 1: The sequence of the primers.

\begin{tabular}{lcc}
\hline & Gene & The sequence of the primers \\
\hline pEGFP-N1:ABHDl6A & F & $5^{\prime}$-primer CGGAATTCATGGCGAAGCTGCTG \\
pEGFP-N1:IFITM3 & $\mathrm{R}$ & $3^{\prime}$-primer CGGGATCCAGGTGCCAGGGCAT \\
& $\mathrm{F}$ & $5^{\prime}$-primer ACGGAATTCATGAATCACACTGTCCAA \\
pCDNA3.1:ABHDl6A & $\mathrm{R}$ & $3^{\prime}$-primer CGGGATCCCTTCCATAGGCCTGGAAGA \\
pEGFP-N1:IFITM3 & $\mathrm{F}$ & $5^{\prime}$-primer CGGAATTCATGGCGAAGCTGCTG \\
& $\mathrm{R}$ & $3^{\prime}$-primer CGGGATCCAGGTGCCAGGGCAT \\
\hline
\end{tabular}

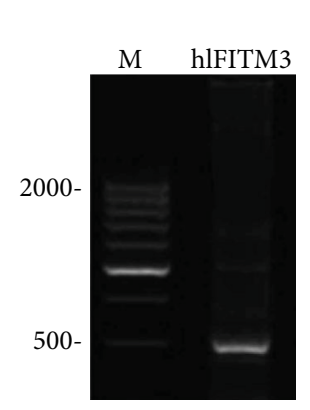

(a)

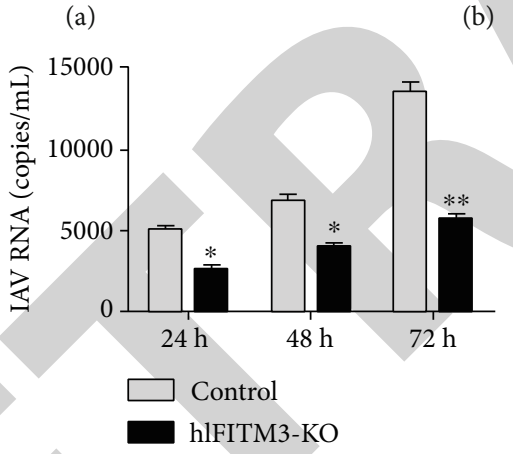

(d)

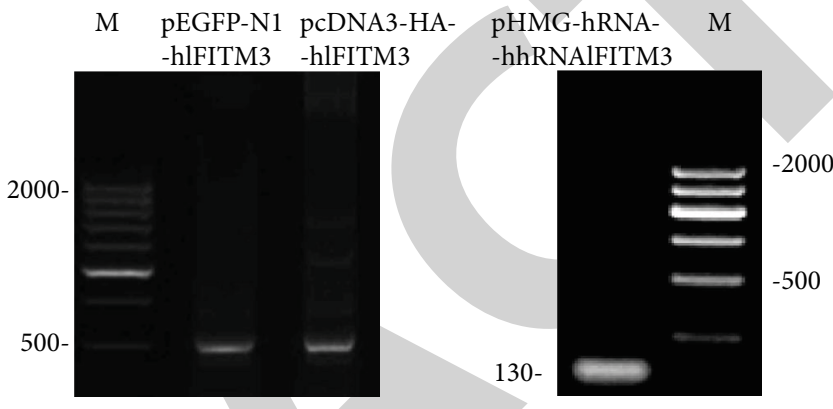

(c)

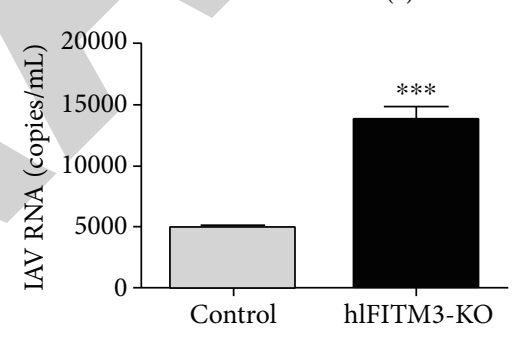

(e)

FIGURE 1: Construction of pEGFP-N1-hlFITM3 and pcDNA3.1-HA-hIFITM3 recombinant plasmids and anti-IAV detection of hIFITM3 in HEK293 cells. (a) Amplification of the target fragment of hIFITM3 (M: DM2000 DNA marker; hIFITM3: hIFITM3 PCR amplified fragment); (b) pEGFP-N1-hlFITM3 and pcDNA3.1-HA-hIFITM3 bacterial cell PCR (M: DM2000 DNA marker; pEGFP-N1-hlFITM3 and pcDNA3.1-HAhIFITM3 PCR validation); (c) pHMG-hRNA-hhRNAIFITM3 (M: DM2000 DNA marker; pHMG-hRNA-hhRNAIFITM3: hhRNAIFITM3 knockout recombinant plasmids); (d) RT-PCR detection of IFITM3 (vs. control: ${ }^{*} P<0.05 ;{ }^{* *} P<0.01$ ); (e) the effects on IAV replication of hIFITM3 knockout in HEK293 cells (vs. control: ${ }^{* * *} P<0.001$ ).

$24 \mathrm{~h}$, they were infected with influenza virus at $1 \mathrm{MOI}$, and the culture supernatant was taken at different time points after infection. Fluorescence quantitative PCR was used to detect the virus copy number. The results showed that hIFITM3 had obvious anti-influenza virus effects. Virus amplification was significantly reduced at $24 \mathrm{~h}$ and $48 \mathrm{~h}$ after infection, when compared with controls. The difference became even more pronounced at $72 \mathrm{~h}$ (Figure $1(\mathrm{~d})$ ).

The constructed knockout plasmid was transfected into HEK293 cells, and a virus infection experiment was carried out. The results of fluorescence quantitative measurement showed that the pHMG-hRNA-hhRNAIFITM3 knockout plasmid was transfected, and the influenza virus infected the hlFITMl3 knockout cells. In contrast, the viral copy number was significantly increased (Figure 1(e)).

3.3. Subcellular Localization of hlFITM3 and hABHD16A. In the yeast transformation of hIFITM3 and hABHD16A, colonies grown on the SD-Leu-Trp solid medium lack leucine (Leu) and tryptophan (Trp), but in the lack of leucine (Leu), colonies were grown on pGBKT7-hIFITM3/pGADT7-hABHD16A on SDLeu-Trp-His solid medium containing tryptophan (Trp) and histidine (His). It shows that hIFITM3 and hABHD16A can interact (Figure 2(a)).

The successfully constructed fusion fluorescent expression vector was transfected into HEK293 cells, and the 
pEGFP-N1/pdhRed-monomer-N1 empty vector was transfected as a control group. Hoechest33342 nuclear staining was performed and observed with a laser confocal microscope. The results showed that hlFITM3 and hABHDl6A were aggregated and localized in the cell membrane structure, respectively. The superimposed pictures show that hlFITM3 and hABHDl6A were colocated in the cell membrane structure (Figure 2(b)). After the plasmid was cotransfected for $24 \mathrm{~h}$, the plasmid-transfected cells were infected with 1 MOI influenza virus, and culturing was continued for $48 \mathrm{~h}$. They were subsequently stained by Hoechest 33342 and observed by laser confocal microscopy. The results showed that after influenza virus infection, there was a clear change in the location of hlFITM3 and hABHDl6A as compared to before infection, and the colocalized area tended to move towards the cell's nuclear area.

3.4. hABHDl6A Has an Inhibitory Effect on IVA. The positive clones were verified by bacterial solution PCR, and the results showed that the pHMG-hRNA-hhRNAABHD16A was successfully constructed (Figure 3(a)). When hABHD16A was knocked out of HEK293 cells, the copy number of IVA increased significantly compared with the control, and the difference observed was significant. This result indicates that hABHD16A has an inhibitory effect on influenza A virus (Figure 3(b)). Once again, in HEK293 cells with an overexpression of hABHDl6A protein, there was no significant difference with the control group after 24 hours of infection with the virus. hABHDl6A affects IVA replication at $48 \mathrm{~h}$ after infection, which can also inhibit the replication of IVA virus at $72 \mathrm{~h}$ after infection (Figure $3(\mathrm{c})$ ).

In HEK293 cells, when there was overexpression of hlFITM3 or hABHD16A alone compared to normal expressing cells, the results showed that hlFITM3 significantly inhibited IVA replication at $24 \mathrm{~h}, 48 \mathrm{~h}$, and $72 \mathrm{~h}$ after infection. When hABHD16A was overexpressed, it also significantly inhibited influenza virus replication at $24 \mathrm{~h}, 48 \mathrm{~h}$, and $72 \mathrm{~h}$ after infection. After cotransformation of pcDNA3.1(+)HA-hlFITM3/pcDNA3.1(+)-HA-hABHDl6A, the amount of virus that was detected at the three time points of infection showed that the inhibitory effect on coexpression of the two proteins against influenza virus was significantly stronger than when they were expressed alone. These findings show that hlFITM3 and hABHDl6A can synergistically inhibit the replication of influenza A virus (Figure 3(d)).

3.5. The Inhibition of IVA Replication by hlFITM3 Is Closely Related to the S-Palmitoylation of hABHDl6A. To determine whether the anti-influenza virus effect of hlFITM3 is related to its palmitoylation, PCR point mutation technology was used to amplify the palmitoylation site mutation (Figure $4(\mathrm{a})$ ) and construct the mutant vector pcDNA3.1(+)-HA-hlFITM3C50A-C5IA-C84A and pcDNA3.1(+)-HA-hlFITM3-C84A eukaryotic expression vector. M-hlFITM3, hlFITM3 \hABHDl6A overexpressing hlFITM3, hABHDl6A, and C50AC51A-C84A site mutations were infected with influenza A virus, and the culture supernatant was taken after $24 \mathrm{~h}$, and the viral copy number was detected by RT-PCR. Compared with the transfection control group, after transfection of
hlFITM3 and hABHDl6A and cotransfection of hlFITM3/hABHDl6A, the replication of influenza virus was significantly inhibited. In the cells transfected with mutant M-hlFITM3, the virus copy number was significantly higher than that in the wild transfected hlFITM3 group, and in cotransfected mutant M-hlFITM3 \hABHDl6A, the virus copy number was higher than that of cotransfected hlFITM3/hABHDl6A. These results indicate that the antiviral effect of hIFITM3 depends on its palmitoylation site, and the function of this site is related to the hABHD16A interaction (Figure 4(b)).

3.6. Cotransfection of hlFITM3 and hABHDl6A Can Reduce the Expression of Inflammatory Factors Caused by IVA. Relative to uninfected cells, in flu virus-infected HEK293 cells, the hlFITM3 gene was significantly increased, and hABHDl6A gene expression was significantly reduced (Figures 5(a) and $5(\mathrm{~b}))$.

When IL-6, TNF- $\alpha$, IL- $1 \beta$, and IL-10 were transfected with hlFITM3 and hABHDl6A, respectively, their expressions increased significantly, while with cotransfection, they decreased significantly, indicating that the interaction of hlFITM3 and hABHDl6A can reduce the expression of inflammatory factors. In the virus-infected group, the expression levels of IL6, TNF- $\alpha$, IL- $1 \beta$, and IL-10 were increased compared with the empty vector control, but the coexpression of hlFITM3 and hABHDl6A decreased IL-6, TNF- $\alpha$, IL- $1 \beta$, and IL-10 expression (Figures 5(d)-5(g)). In HEK293 cells, compared with control cells transfected with empty vectors, the expression level of the monocyte chemoattractant protein-1 (MCP-1) gene was significantly reduced in single transfection and cotransfection; in the infected virus group, the expression level of MCP-1 gene was lower (Figure 5(c)). The expression level of the COX2 gene was significantly increased when transfected with hlFITM3 and hABHDl6A as well as when cotransfected, respectively, while infection with influenza virus could reduce the expression level of COX2 (Figure 5(h)).

\section{Discussion}

This study confirmed that hIFITM3 has an effect of inhibiting IVA replication. Furthermore, it was found that hIFITM3 interacts with hABHD16A, following which it can better inhibit the replication of IVA and the inflammatory response caused by the disease process. The above results provide a possible explanation for the mechanism by which hIFITM3 inhibits the replication of IVA and offers theoretical support for clinically improving interferon to treat influenza infection.

Interferon-induced transmembrane proteins (IFITMs) are small transmembrane proteins induced by interferons (interferon, IFNs) [6]. Type I and type II interferons can induce the expression of human IFITM1, IFITM2, and IFITM3. As a specific viral restriction molecule, the virus is prevented from passing through the lipid bilayer of the cell and entering the cytoplasm. Human IFITM1, IFITM2, and IFITM3 are widely expressed in various tissues, and studies have found that IFITM3 is expressed in the upper respiratory tract and lung pleural cells. Interferon-induced transmembrane protein IFITM3 has a strong inhibitory effect on the 
SD-Leu-Trp

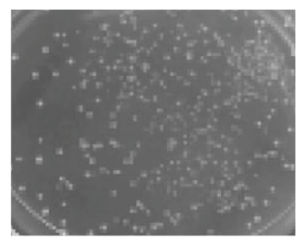

pGBKT7-hlFITM3 /pGADT7-hABHD16A

hlFITM3

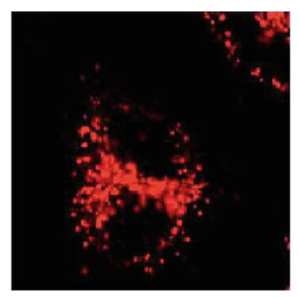

SD-His-Leu-Trp

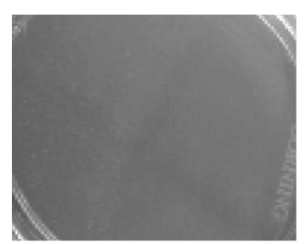

pGBKT7-hlFITM3

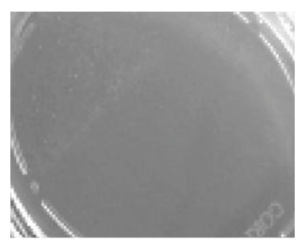

pGADT7-hABHD16A

(a)

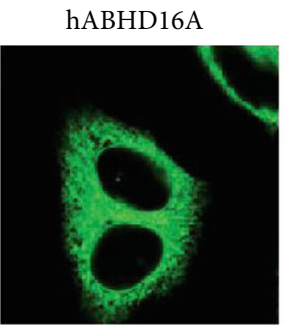

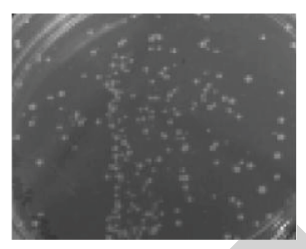

pGBKT7-hlFITM3

/pGADT7-hABHD16A

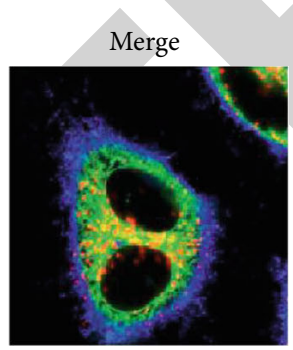

(b)

FIgURE 2: Subcellular localization of hlFITM3 and hABHD16A. (a) Cotransfection of yeast two-hybrid screening. (b) Subcellular localization of hIFITM3 and hABHD16A in HEK293 cell $(\times 400)$.

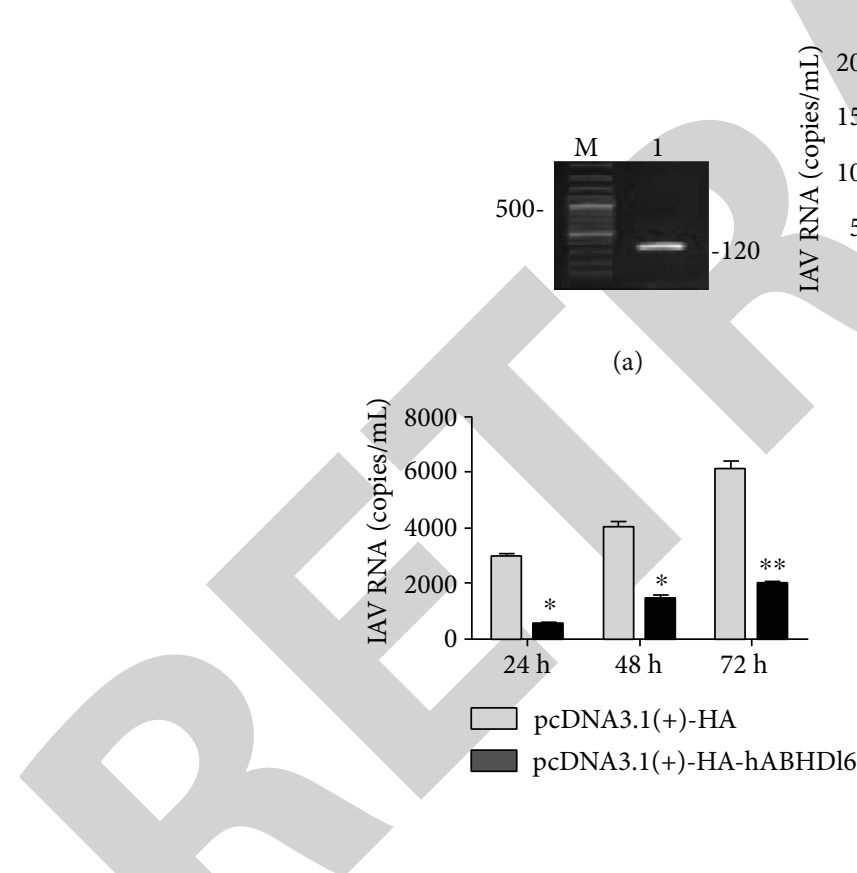

(c)

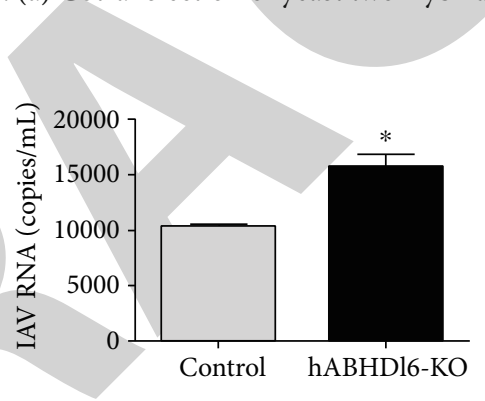

(b)

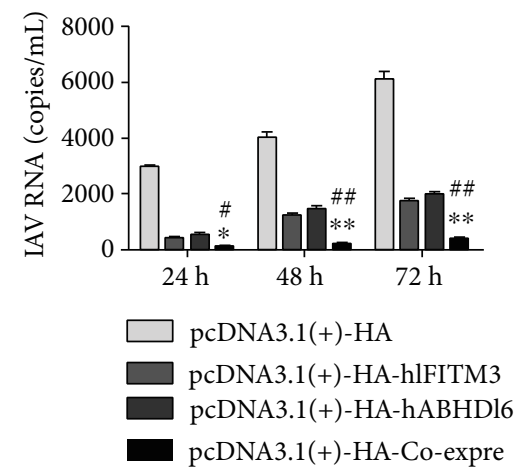

(d)

FIGURE 3: hABHDl6A has an inhibitory effect on influenza virus. (a) PCR validation of recombinant plasmid pHMG-hRNA-hhRNAABHD16A (M: DM2000 DNA marker; 1: pHMG-hRNA-hhRNAABHD16A); (b) the inhibition of IAV in HEK293 cells hABHD16A knockout (vs. control: ${ }^{*} P<0.05$ ). (c) IAV copy number in hABHDl6A-overexpressing HEK293, at $24 \mathrm{~h}, 48 \mathrm{~h}$, and $72 \mathrm{~h}$ (vs. control: ${ }^{*} P<0.05$; ${ }^{* *} P<0.01$ ). (d) Effects of coexpression of hIFITM3 and hABHD16A on IAV replication (vs. pcDNA3.1 (+)-HA-hIFITM3: ${ }^{*} P<0.05$; ${ }^{* *} P<0.01$; vs. pcDNA3.1 (+)-HA-hABHD16A: $\left.{ }^{\#} P<0.05 ;{ }^{\# \#} P<0.01\right)$.

replication of various viruses [7,8]. IFITM3 is expressed on the cell membrane and exists on the cytoplasm as particles. IFITM3 plays a role in different cellular processes, including immune cell regulation, germ cell maturation, cell proliferation, and heart development $[9,10]$. Influenza A virus is an
RNA virus that is prone to mutation in the genome. The mutated virus exhibits increased infectivity, cross-species transmission and other phenomena, and even zoonotic conditions that threaten human health. Brass and Shapira and others first proposed IFITM3 as a potential limiting factor 


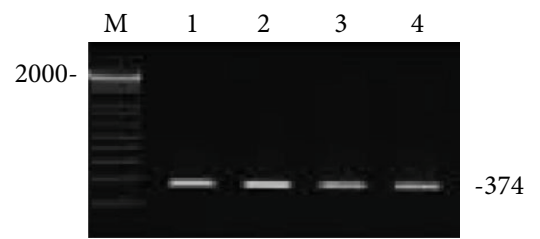

(a)

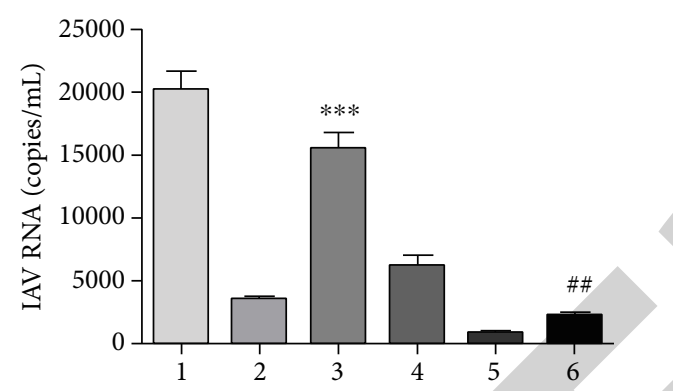

(b)

FIgURe 4: (a) hIFITM3 mutant fragment PCR amplification (M: DM2000 DNA marker; 1-4: hIFITM3-F, hIFITM3-R PCR amplification of the target fragment); (b) effects of coexpression of hIFITM3 and hABHDl6A on IAV replication (vs. $2:{ }^{* * *} P<0.001$; vs. 5: ${ }^{\# \#} P<0.01$ ). 1 : vector; 2: overexpression hIFITM3; 3: overexpression hABHDl6A; 4: overexpression of hIFITM3 with mutations at 50A-C51A-C84A; 5: overexpression hIFITM3/hABHD16A; 6: overexpression of hIFITM3/hABHDl6A with mutations at 50A-C51A-C84A.

for IAV in 2009. Bailey et al. demonstrated that IFITM3deficient mice not only failed to clear IAV but also found that there was an increase in the mortality rate after virus infection, as well as the risk of other diseases [11]. In terms of the mechanism of action, in their research, Huang et al. found that IFITM3 inhibits IAV infection by preventing the release of the riboprotein complexes about the cytoplasm, rather than through the inhibition of viral binding and entry into cells. Everitt et al. found that the single nucleotide polymorphism in the IFITM3 allele is related to the susceptibility to IAV $[12,13]$. In addition, Gerlach et al. reported that the toxicity and spread of IAV are also related to the $\mathrm{pH}$ of the cell membrane and that the stable expression of IFITM2 and IFITM3 proteins can effectively reduce virus replication $[14,15]$. In this study, influenza virus replication was inhibited from HEK293 cells overexpressing hlFITM3 protein. The virus was further suppressed via interaction with the protein hABHDl6A.

The ABHD protein family has now been predicted to contain at least 19 proteins [16]. This family of proteins has a typical domain of the $\alpha / \beta$-hydrolase superfamily. The family contains proteases, lipases, esterases, dehalogenases, and peroxidases and oxide hydrolysis enzymes, etc. [17-19]. In the ABHD family, several members of the substrate have been identified as having the ability to regulate glycerophospholipid metabolism, and they may also play a role in lipid and energy metabolism $[11,20]$. Therefore, this family of proteins has been described as potential regulators for lipid metabolism and signal transduction. The conserved structural motifs shared by these proteins suggest a synergistic role in lipid synthesis and degradation. The functional activity identification of the ABHD family has been reported, with the delineation of substrates and their connection to diseases that alter lipid metabolism in humans [21]. Existing predictions indicated that $\mathrm{ABHD}$ protein involves both hydrolase and acyl transferase activities. ABHD family proteins play an important role in physiological regulation, drug target screening, tumorigenesis, etc. Existing studies had indicated that $\mathrm{ABHD}$ is expected to become a new drug target. Among them, ABHD2 is predicted to have hydrolytic enzyme catalytic activity. Compared with wild-type mice, ABHD2 has been shown to be involved in smooth muscle cell migration and intimal thickening of vascular smooth muscle cells in homozygous mice [22]. Antisense oligonucleotides can be used to downregulate ABHD2 without affecting host cell physiology, blocking hepatitis B virus replication and expression. Indeed, the data indicate that this gene can be used as a new target for anti-HBV drug development. ABHD7 is predicted to negatively regulate the activity of epoxide lipids. Epoxy hydrolase 3 (EH3), or ABHD9, is associated with high expression levels in the skin and upper digestive tracts of mice. It is speculated that sEH inhibitors may be of value in the treatment of hypertension and type 2 diabetes. ABHD16A is a member of the $\alpha / \beta$-hydrolase domaincontaining (ABHD) family of metabolic serine hydrolases, also known as leukocyte antigen-B- (HLA-B-) related transcript 5 (HLA-B-associated transcript 5, BAT5) [23]. It has been reported that human ABHD16A is located on human chromosome 6 and has 21 exons and four transcripts. Existing studies had shown that the four transcripts contain two noncoding long-chain RNAs.

Protein palmitoylation is an important lipidation modification, which plays an important role in the transport of proteins, the location and function of organelles, cell signaling, metabolism, and the occurrence of apoptotic diseases and cancelation. Studies have shown that the S-palmitoylation site in the amino acid sequence of IFITM3 is essential for its function [24]. The results of this study on the antiinfluenza virus effect of the mutants showed that after the corresponding mutation of the cysteine site, the effect of the virus was significantly weakened, similar to other reports related to IFITM3. Based on the results of subcellular localization, it has been speculated that this posttranslational S-palmitoylation modification may affect the binding of influenza virus to the membrane, as well as the separation, transport, and stability of membrane domains. This study also proved that hABHDl6A can effectively inhibit influenza virus and initially showed that it may interact with hlFITM3 to resist the possible mechanism of influenza virus replication.

This study also found that the expressions of hlFITM3 and hABHDl6A were significantly downregulated after the cells were infected with influenza virus, indicating that at the detected time point, the virus invasion led to changes in the expression of hlFITM3 and hABHDl6A, which suggests 


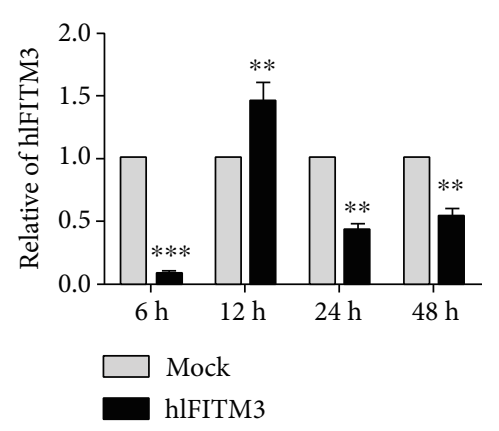

(a)

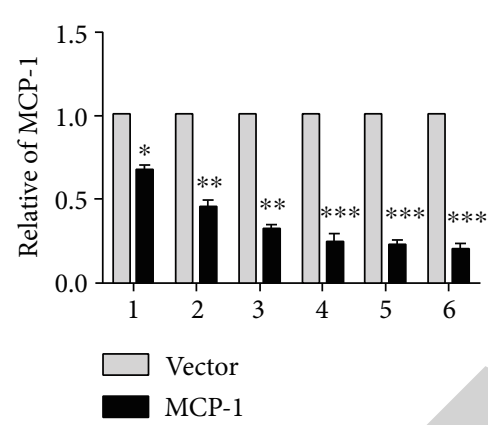

(c)

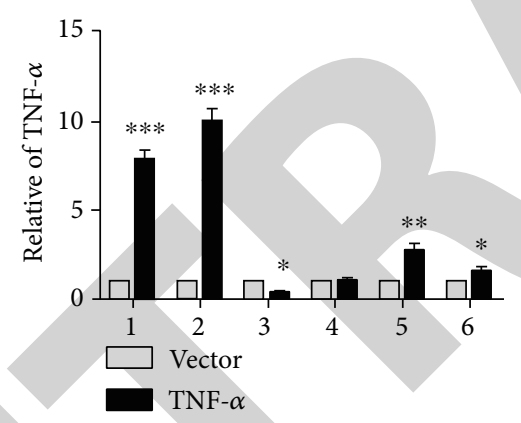

(e)

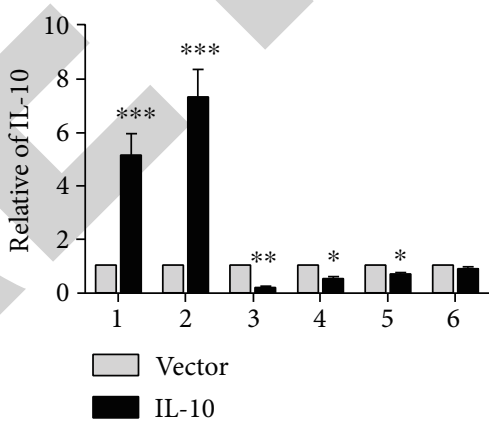

(g)

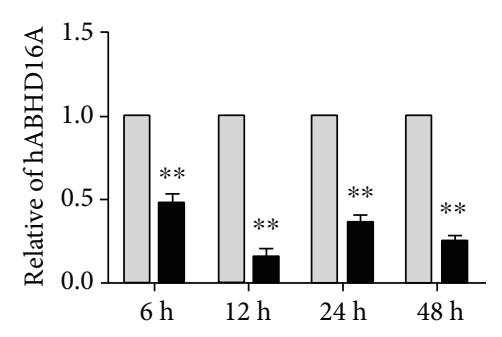

$\square$ Mock

hABHD16A

(b)

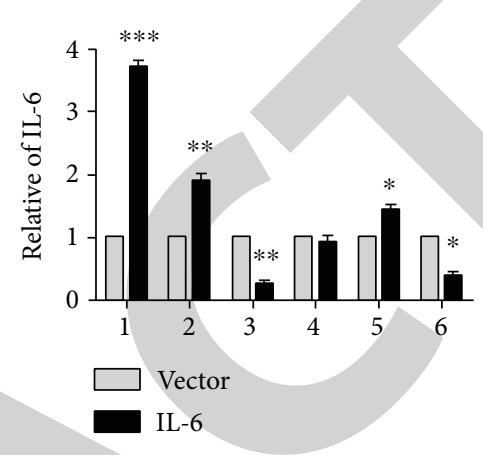

(d)

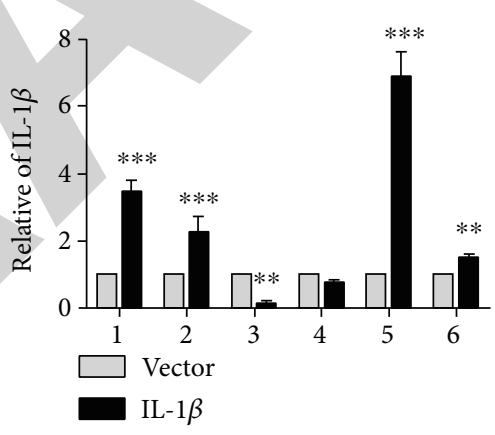

(f)

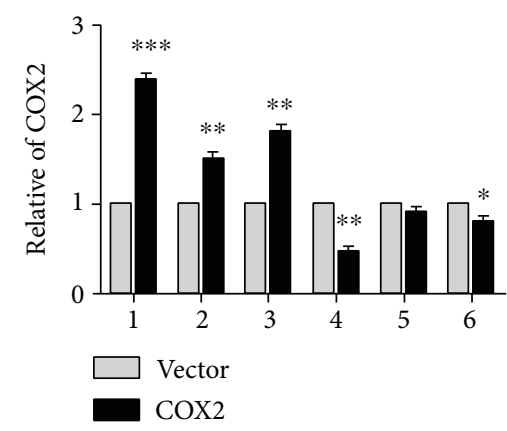

(h)

FIGURE 5: Effect of hIFITM3 and hABHDl6A on the expression of inflammatory factors. (a) hIFITM3 expression levels after IAV infection (vs. mock: ${ }^{*} P<0.05,{ }^{* *} P<0.01$, and ${ }^{* * *} P<0.001$ ). (b) hABHD16A expression after IAV infection (vs. mock: ${ }^{*} P<0.05,{ }^{* *} P<0.01$, and $\left.{ }^{* * *} P<0.001\right)$. (c-h) Effects on the expression of inflammatory factors (MCP-1, IL-6, TNF- $\alpha$, IL-1 $\beta$, IL-10, and COX2) after overexpression of hIFITM3 and/or hABHDl6A in HEK293 cells (vs. vector: ${ }^{*} P<0.05,{ }^{* *} P<0.01$, and ${ }^{* * *} P<0.001$ ). 1: hIFITM3; 2 : hABHDl6A; 3: hIFITM3/hABHDl6A; 4: hIFITM3 (IAV); 5: hABHDl6A (IAV); 6: hIFITM3/hABHDl6A (IAV).

that these two genes may be involved in the regulation of virus invasion. However, whether downregulation of expression is due to immune escape of the virus needs further study.
And at different time points of influenza virus invasion, the hABHDl6A gene was significantly reduced. After 48 hours of infection with influenza virus, it was found that hlFITM3 
returned to a level close to that of the control group, which may indicate that the gene functions as the early stage of influenza virus invasion. In the early stage of influenza virus invasion (12 h), the expression levels of hlFITM3 and hABHDl6A genes were significantly increased, indicating an important suppression role in the process of influenza virus invasion. In this study, it was found that hlFITM3, as the main antiviral protein, was associated with significant biological activity in the process of virus invasion, which is consistent with previous research findings related to the antiviral effects of human IFITMs.

TNF- $\alpha$ is an important inflammation-related factor, which plays a key role in inflammation, autoimmunity, malignant tumor development, and apoptosis [25]. Existing research results indicate that influenza can cause elevated blood TNF- $\alpha$, which has a discernible inhibitory effect on virus replication and, at the same time, recognizes the signals of the upstream cytokines IL-1 and IL-6, thus facilitating a response to sepsis caused by severe influenza [26, 27]. This study found that overexpression of hlFITM3 and hABHDl6A can promote significant expression of this cytokine. After overexpression of hlFITM3 and hABHDl6A in cells infected with influenza virus, it was found that the expression level of the factor was significantly reduced, further indicating that TNF- $\alpha$ is affected by influenza virus, and coexpression of both proteins led to a reduction in the level of TNF- $\alpha$. IL$1 \beta$ is a proinflammatory cytokine that can be expressed by many cell types and can be endogenous and competitive with IL-1 receptor antagonists (IL-IRA). Anti-inflammatory cytokines produced by tissues are suppressed.

IL- $1 \beta$ is an important proinflammatory cytokine of the innate immune response. After overexpression of hlFITM3, compared with the overexpression of influenza virus infection, IL- $1 \beta$ expression is significantly reduced. This is consistent with the results that IL- $1 \beta$ plays a key role in the inflammatory response by activating immune cells and inducing many secondary proinflammatory cytokines $[28$, 29]. The experimental results of this study indicate that overexpression of hlFITM3 and hABHDl6A can promote the expression of this cytokine, and the expression of this factor was not detected after cotransfection. Repeated experiments failed to detect presumed coexpression on multiple occasions. Later, mRNA levels were too low to be detected. Infected with influenza virus after coexpression, this factor was found to be upregulated. The results related to the effects of hlFITM3 and hABHDl6A on the expression of inflammatory factors suggest that the interaction of the two may play an important role in effectively balancing inflammation.

In conclusion, the research results obtained in this research broadened the antiviral spectrum of IFITM3, and the identification and function as its interacting proteins are expected to expand the direction of future research, to further explain the antiviral mechanism of IFITM3, with an analysis of the host cell in the defense against pathogenic microorganisms. The mechanism provides a strong theoretical research foundation. IFITM3 and ABHD16A may be used as new targets and potential antiviral factors in the future for the prevention and control of infectious diseases. Furthermore, future research on the anti-influenza mecha- nism of hlFITM3 and hABHDl6A will not only help to improve our understanding of innate immunity in the process of resisting the virus but also provide research ideas for the study about the resistance of other viruses.

\section{Data Availability}

The data used to support the findings of this study are available from the corresponding author upon request.

\section{Conflicts of Interest}

The authors declare that there is no conflict of interest regarding the publication of this paper.

\section{Authors' Contributions}

Liang Chen designed the study, carried out the test, and drafted the manuscript; Limei Zhu carried out the test and revised the manuscript; and Jun Chen carried out the test and analyze data. All authors agree with the article submission. All authors read and approved the final manuscript.

\section{Acknowledgments}

This study was funded by Beijing JST research (ZR-201921).

\section{References}

[1] L. M. Wakim, N. Gupta, J. D. Mintern, and J. A. Villadangos, "Enhanced survival of lung tissue-resident memory $\mathrm{CD}^{+} \mathrm{T}$ cells during infection with influenza virus due to selective expression of IFITM3," Nature Immunology, vol. 14, no. 3, pp. 238-245, 2013.

[2] X. Sun, H. Zeng, A. Kumar, J. A. Belser, T. R. Maines, and T. M. Tumpey, "Constitutively expressed IFITM $_{3}$ protein in human endothelial cells poses an early infection block to human influenza viruses," Journal of Virology, vol. 90, no. 24, pp. 11157-11167, 2016.

[3] Y. Pan, P. Yang, T. Dong et al., "IFITM3 Rs12252-C variant increases potential risk for severe influenza virus infection in Chinese population," Frontiers in cellular and infection microbiology, vol. 7, 2017.

[4] N. M. Chesarino, T. M. McMichael, and J. S. Yount, "E 3 ubiquitin ligase $\mathrm{NEDD}_{4}$ promotes influenza virus infection by decreasing levels of the antiviral protein IFITM $_{3}$," PLoS Pathog, vol. 11, no. 8, article e1005095, 2015.

[5] G. A. D. Blyth, W. F. Chan, R. G. Webster, and K. E. Magor, "Duck interferon-inducible transmembrane protein 3 mediates restriction of influenza viruses," Journal of Virology, vol. 90, no. 1, pp. 103-116, 2015.

[6] D. C. Yánez, S. Ross, and T. Crompton, "The IFITM protein family in adaptive immunity," Immunology, vol. 159, no. 4, pp. 365-372, 2020.

[7] S. E. Smith, M. S. Gibson, R. S. Wash et al., "Chicken interferon-inducible transmembrane protein 3 restricts influenza viruses and Lyssavirusesin vitro," Journal of Virology, vol. 87, no. 23, pp. 12957-12966, 2013.

[8] Y. Liao, M. U. Goraya, X. Yuan, B. Zhang, S.-H. Chiu, and J.-L. Chen, "Functional involvement of interferon-inducible 
transmembrane proteins in antiviral immunity," Frontiers in microbiology, vol. 10, article 1097, 2019.

[9] F. Siegrist, M. Ebeling, and U. Certa, "The small interferoninduced transmembrane genes and proteins," Journal of Interferon \& Cytokine Research, vol. 31, no. 1, pp. 183-197, 2011.

[10] G. Shi, O. Schwartz, and A. A. Compton, "More than meets the I: the diverse antiviral and cellular functions of interferoninduced transmembrane proteins," Retrovirology, vol. 14, no. $1,2017$.

[11] C. C. Lord, G. Thomas, and J. M. Brown, "Mammalian alpha beta hydrolase domain (ABHD) proteins: lipid metabolizing enzymes at the interface of cell signaling and energy metabolism," Biochimica et Biophysica Acta, vol. 1831, no. 4, pp. 792-802, 2013.

[12] P. Horby, N. Y. Nguyen, S. J. Dunstan, and J. Kenneth Baillie, "An updated systematic review of the role of host genetics in susceptibility to influenza," Influenza and other respiratory viruses, vol. 7, Suppl 2, pp. 37-41, 2013.

[13] S. P. John, C. R. Chin, J. M. Perreira et al., "The CD225 domain of IFITM3 is required for both IFITM protein association and inhibition of influenza A virus and dengue virus replication," Journal of Virology, vol. 87, no. 14, pp. 7837-7852, 2013.

[14] T. Gerlach, L. Hensen, T. Matrosovich et al., "pH optimum of hemagglutinin-mediated membrane fusion determines sensitivity of influenza A viruses to the interferon-induced antiviral state and IFITMs," Journal of Virology, vol. 91, no. 11, article e00246, 2017.

[15] M. Hu, G. Yang, J. DeBeauchamp et al., "HA stabilization promotes replication and transmission of swine H1N1 gamma influenza viruses in ferrets," Elife, vol. 9, article e56236, 2020.

[16] J. Xu, W. Gu, K. Ji, Z. Xu, H. Zhu, and W. Zheng, "Sequence analysis and structure prediction of ABHD16A and the roles of the ABHD family members in human disease," Open Biology, vol. 8, no. 5, article 180017, 2018.

[17] L. Kind and P. Kursula, "Structural properties and role of the endocannabinoid lipases ABHD6 and ABHD12 in lipid signalling and disease," Amino Acids, vol. 51, no. 2, pp. 151-174, 2019.

[18] A. Vijayakumar, P. Vijayaraj, A. K. Vijayakumar, and R. Rajasekharan, "The Arabidopsis ABHD11 mutant accumulates polar lipids in leaves as a consequence of absent acylhydrolase activity," Plant Physiology, vol. 170, no. 1, pp. 180-193, 2015.

[19] J. L. Blankman, J. Z. Long, S. A. Trauger, G. Siuzdak, and B. F. Cravatt, "ABHD12 controls brain lysophosphatidylserine pathways that are deregulated in a murine model of the neurodegenerative disease PHARC," Proceedings of the National Academy of Sciences of the United States of America, vol. 110, no. 4, pp. 1500-1505, 2013.

[20] G. Liu, Y. Ruan, J. Zhang et al., “ABHD11 is critical for embryonic stem cell expansion, differentiation and lipid metabolic homeostasis," Frontiers in cell and developmental biology, vol. 8, 2020.

[21] C. C. Lord, J. L. Betters, P. T. Ivanova et al., "CGI-58/ABHD5derived signaling lipids regulate systemic inflammation and insulin action," Diabetes, vol. 61, no. 2, pp. 355-363, 2012.

[22] S. Jin, G. Zhao, Z. Li et al., "Age-related pulmonary emphysema in mice lacking alpha/beta hydrolase domain containing 2 gene," Biochemical and Biophysical Research Communications, vol. 380, no. 2, pp. 419-424, 2009.
[23] T. Spies, G. Blanck, M. Bresnahan, J. Sands, and J. L. Strominger, "A new cluster of genes within the human major histocompatibility complex," Science, vol. 243, no. 4888, pp. 214-217, 1989.

[24] W. J. Melvin, T. M. McMichael, N. M. Chesarino, J. C. Hach, and J. S. Yount, "IFITMs from Mycobacteria confer resistance to influenza virus when expressed in human cells," Viruses, vol. 7, no. 6, pp. 3035-3052, 2015.

[25] B. L. Salomon, M. Leclerc, J. Tosello, E. Ronin, E. Piaggio, and J. L. Cohen, "Tumor necrosis factor $\alpha$ and regulatory T cells in oncoimmunology," Frontiers in immunology, vol. 9, 2018.

[26] A. Iwasaki and P. S. Pillai, "Innate immunity to influenza virus infection," Nature Reviews. Immunology, vol. 14, no. 5, pp. 315-328, 2014.

[27] Y. Ding, L. Zeng, R. Li et al., "The Chinese prescription lianhuaqingwen capsule exerts anti-influenza activity through the inhibition of viral propagation and impacts immune function," BMC Complementary and Alternative Medicine, vol. 17, no. 1, p. 130, 2017.

[28] E. A. Miao, C. M. Alpuche-Aranda, M. Dors et al., "Cytoplasmic flagellin activates caspase- 1 and secretion of interleukin $1 \beta$ via Ipaf," Nature Immunology, vol. 7, no. 6, pp. 569-575, 2006.

[29] M. R. M. Cavalcanti, F. R. S. Passos, B. S. Monteiro et al., "HPLC-DAD-UV analysis, anti-inflammatory and antineuropathic effects of methanolic extract of Sideritis bilgeriana (lamiaceae) by NF- $\kappa$ B, TNF- $\alpha$, IL- $1 \beta$ and IL-6 involvement," Journal of Ethnopharmacology, vol. 265, article 113338, 2021. 